\title{
Impact of Neonatal Frenotomy on the Breastfeeding Rate at Discharge from the Maternity Ward: A Prospective, Cohort Study
}

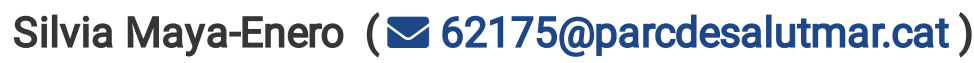

Hospital del Mar, Universitat Pompeu Fabra

Luis Ruiz-Guzmán

Gavà Salut Familiar

Júlia Candel-Pau

Hospital del Mar, Universitat Pompeu Fabra

Xavier Duran-Jordà

IMIM (Institut Hospital del Mar d'Investigacions Mèdiques) (Hospital del Mar Institute for Medical Research)

María Ángeles López-Vílchez

Hospital del Mar, Universitat Pompeu Fabra

\section{Research Article}

Keywords: ankyloglossia, breastfeeding difficulty, frenotomy, nipple pain, tongue-tie

Posted Date: October 21st, 2021

DOI: https://doi.org/10.21203/rs.3.rs-990464/v1

License: (c) (1) This work is licensed under a Creative Commons Attribution 4.0 International License. Read Full License 


\section{Abstract \\ Background}

Ankyloglossia may lead to an early abandonment of breastfeeding. Performing a frenotomy could increase the breastfeeding rate at discharge from the maternity ward.

\section{Methods}

This prospective cohort study included all the neonates born in our center in 2018 (1392). We offered a frenotomy to all tongue-tied patients. We determined how many frenotomies we performed (422), whether breastfeeding improved in the short term, and compared the breastfeeding rates between treated and untreated tongue-tied and non-tongue-tied neonates. Quantitative variables were described using the mean and standard deviation, and compared using a Student's t-test. Rates of breastfeeding were compared using the Pearson chi square. Significance was set at the $p<0.05$ level.

\section{Results}

The breastfeeding rate at discharge was higher among tongue-tied infants $(92.1 \%)$ than non-tongue-tied (84.2\%), and higher among treated than untreated neonates (93.1 vs $75.9 \%$, respectively).

\section{Conclusions}

Frenotomy could help increase the breastfeeding rate at discharge among tongue-tied neonates.

\section{Trial registration:}

Not applicable

\section{Background}

The lingual frenulum is a submucosal band of connective tissue or a membrane that inserts on the tip of the tongue or along its undersurface [1-3]. We refer to ankyloglossia, or tongue-tie, when a thickened, tightened or shortened lingual frenulum restricts tongue movement $[1,2,4-9]$. The reported prevalence of ankyloglossia varies between less than 1-12.1\% depending upon the study population and criteria used to define and grade ankyloglossia, as standardized diagnostic criteria do not exist to date $[1-4,6,7,9-$ 17]. However, some authors have found higher prevalences $[8,18]$. We observed a prevalence of ankyloglossia of 32.5\% among our neonates born in 2018 [19]. Most studies have focused their attention 
to the so-called "anterior tongue-ties", whereas the true prevalence of "posterior tongue-ties" remains unknown [14].

Breastfeeding difficulties are common in the neonatal period. Evidence shows that ankyloglossia is a potential cause of infant feeding problems, although not the only one. Retrognathia, nasal or airway obstruction, laryngopharyngeal reflux, cleft palate, etc. must be ruled out as well $[6-9,14-16]$. Neonatal ankyloglossia is a subject of ongoing controversy among healthcare professionals. While some believe that it is rarely symptomatic, others believe that it may lead to several problems. Even though the majority of tongue-tied infants are able to breastfeed, they are more likely to present poor latch onto the breast and are less efficient at breastfeeding, with resultant low milk transfer and poor weight gain, and maternal nipple pain which may result in untimely weaning $[1-4,6-10,13-18,20-22]$. Whereas an asymptomatic lingual frenulum does not need to be treated, ankyloglossia that interferes with breastfeeding is an indication for frenotomy. Performing a frenotomy in tongue-tied neonates with breastfeeding difficulties has positive effects $[1-9,11,13-17,24,25]$. Potential adverse effects include bleeding, infection, ulceration, pain, damage to the tongue and submandibular ducts, and recurrence, although most recent studies report little discomfort and few adverse effects $[1-4,6,7,9,11,13,14,16,20,23,26]$.

Our hypotheses were that the surgical correction of tongue-ties in the first days would decrease nipple pain in the short term and increase breastfeeding at discharge from the maternity ward (48 to 72 hours after birth) and that the breastfeeding rate would be higher among treated than untreated tongue-tied neonates. We took other risk factors associated with unsuccessful breastfeeding into account, such as lack of breastfeeding experience, prematurity, low birth weight and being born by cesarean [25].

\section{Methods}

We conducted a prospective, cohort study of the neonates born at a tertiary care hospital with a reference area of about 400,000 people which experiences approximately 1,400 births per year. We included all the neonates born in our center between January 1 st and December 31st, 2018. At least one of the three staff neonatologists evaluated each neonate for the presence of ankyloglossia as part of the routine neonatal evaluation and graded ankyloglossia based on Coryllos's classification [27]. We assessed impact of the frenulum on tongue appearance and function using the Hazelbaker score: a patient was tongue-tied if it scored $\leq 8$ points in appearance and/or $\leq 11$ points in function [28]. Advice and help with positioning and latching onto the breast were given by IBCLC (International Board Certified Lactation Consultant) to all the mothers regardless of the presence of a tongue-tie and its treatment. We offered a frenotomy to all tongue-tied neonates. One of the three staff neonatologists performed it in the neonatal unit if the parents consented to after being orally informed of the potential benefits and risks. To perform it, we swaddled the neonate with a towel, gave it $24 \%$ sucrose as analgesia and let it suck for 2 minutes before the procedure. We placed a sterile groove director under the tongue, holding the frenulum in place with visualization of tongue base and frenulum, and snipped the frenulum with blunt-ended scissors along the underside of the tongue to its base just proximal to the genioglossus muscle $[6,7,13,14,16,17,27]$. Following the frenotomy, we returned the neonate to the mother for breastfeeding. At that time and until 
discharge from the maternity ward, we assessed whether there was a short-term improvement in terms of a self-reported, subjective decrease of nipple pain and/or improved latch according to the LATCH score. The LATCH score evaluates the actual infant latch, audible swallowing, type of nipple, comfort, and hold/positioning during breastfeeding $[16,17,29]$. Even though there are not clinical trials that demonstrate the advantage of performing postoperative "tongue exercises" [6], we recommended them mainly to avoid readhesion during scarring [30]. We collected demographic variables (sex, maternal age, birth weight, weight at discharge, birth mode), the presence of ankyloglossia, treatment for ankyloglossia, improvement after the frenotomy, and type of feed at discharge.

Our Ethics Committee approved the study (reference number: 2019/8537/I), which was conducted in accordance with the Declaration of Helsinki.

Statistical analyses: Quantitative variables (gestational age, birth weight, weight at discharge), which were normally distributed, were described using the mean and standard deviation, and compared using a Student's t-test. We compared the population of tongue-tied neonates (treated and untreated) with the total of neonates to verify that the samples were homogeneous in terms of gestational age, birth weight and sex. Rates of breastfeeding between the three groups were compared using the Pearson chi square. Significance was set at the $p<0.05$ level. To perform statistical analyses, we used STATA version 15.1 (StataCorp, College Station, TX, USA).

\section{Results}

A total of 1392 neonates were born at our center in 2018. We excluded seven who were transferred to higher complexity hospitals because they were either extremely preterm or needed intensive care. Thus, we studied 1385 neonates (99.5\%), who were mostly healthy, full-term or late preterm. Of them, 451 $(32.5 \%)$ had a tongue-tie. Table 1 shows the characteristics of tongue-tied vs non-tongue-tied neonates. There were no differences in terms of gestational age, birth weight, weight at discharge, weight loss, prematurity rate and birth mode. The differences in maternal age were not clinically relevant (31.6 vs 30.9 years). We found a male to female ratio of 1.4:1 among tongue-tied neonates. The mean Hazelbaker score from tongue-tied infants was 5.8 points (SD 1.7, range 1-9) for appearance and 7.8 (SD 1.8, range 1-13) for function. Frenotomy was performed in 422 patients, and 402 improved according to the mothers' self-report and the LATCH score. Twenty-nine parents declined the frenotomy. All the interventions were performed without significant incidents other than ten cases of minimal bleeding that ceased with pressure with a gauze and a case that required stitches. 
Table 1

Demographic characteristics of patients with and without ankyloglossia.

\begin{tabular}{|c|c|c|c|c|}
\hline & $\begin{array}{l}\text { Tongue-tied } \\
\text { infants } \\
n=451 \text { (\%) }\end{array}$ & $\begin{array}{l}\text { Non-tongue-tied } \\
\text { infants } \\
n=934(\%)\end{array}$ & $\begin{array}{l}\text { Total of } \\
\text { neonates } \\
n=1385(\%)\end{array}$ & p-value \\
\hline Male newborn & $265(58.7)$ & 457 (48.9) & $722(52.1)$ & $0.003^{a *}$ \\
\hline Ratio male:female & 1.4:1 & $1: 1$ & 1.1:1 & \\
\hline Maternal age (years) (SD) & $31.6(6.0)$ & $30.9(6.3)$ & $31.1(6.2)$ & $0.038^{\mathrm{b} *}$ \\
\hline $\begin{array}{l}\text { Gestational age (weeks) } \\
\text { (SD) }\end{array}$ & $39^{0 / 7}\left(2^{3 / 7}\right)$ & $39^{1 / 7}\left(1^{5 / 7}\right)$ & $39^{1 / 7}\left(2^{0 / 7}\right)$ & $0.153^{b}$ \\
\hline Birth weight (g) (SD) & $3180(540)$ & 3204 (530) & 3196 (533) & $0.419^{b}$ \\
\hline Weight at discharge & $3008(491)$ & 3045 (483) & $3033(486)$ & $0.184^{b}$ \\
\hline Birth mode: & $294(65.2)$ & $652(69.8)$ & $946(68.3)$ & $0.164^{\mathrm{a}}$ \\
\hline Vaginal & $51(11.3)$ & $80(8.6)$ & $131(9.5)$ & \\
\hline Instrumented & $106(23.5)$ & $202(21.6)$ & 308 (22.2) & \\
\hline \multicolumn{5}{|l|}{ Cesarean } \\
\hline Feeding choice at discharge: & $415(92.1)$ & 787 (84.2) & $1202(86.8)$ & $<0.001^{a *}$ \\
\hline Breastfed & $16(3.5)$ & $40(4.3)$ & $56(4.0)$ & \\
\hline Breastfed and bottle-fed & $20(4.4)$ & $107(11.5)$ & $127(9.2)$ & \\
\hline \multicolumn{5}{|l|}{ Bottle-fed } \\
\hline First baby & $239(52.8)$ & $418(44.7)$ & $657(47.4)$ & $0.030^{\mathrm{a} *}$ \\
\hline $\begin{array}{l}\text { Previous breastfeeding } \\
\text { experience }\end{array}$ & $153(33.8)$ & $375(40.1)$ & $528(38.1)$ & $0.126^{\mathrm{a}}$ \\
\hline Prematurity & $45(9.9)$ & $94(10.1)$ & 139 (10.0) & $0.573^{\mathrm{a}}$ \\
\hline Frenotomy & 422 (93.6) & $0(0)$ & $422(30.5)$ & $<0.001^{a *}$ \\
\hline Improvement & 402 (95.2) & -- & - & -- \\
\hline
\end{tabular}

Table 2 shows feeding choice at discharge. Neonates with treated ankyloglossia had a significantly higher rate of exclusive breastfeeding than neonates without ankyloglossia and higher than neonates with untreated ankyloglossia $(p<0.001)$. 
Table 2

Feeding choice at discharge from the maternity ward in tongue-tied patients who underwent frenotomy, in untreated, tongue-tied patients, and in non-tongue-tied patients.

\begin{tabular}{|lllll|}
\hline \multicolumn{2}{|l|}{ At discharge from the maternity ward } & & & \\
& $\begin{array}{l}\text { Tongue-tied and } \\
\text { frenotomy, } \\
\mathrm{n}=422(\%)\end{array}$ & $\begin{array}{l}\text { Tongue-tied without } \\
\text { frenotomy, } \mathrm{n}=29(\%)\end{array}$ & $\begin{array}{l}\text { Non- } \\
\text { tongue- } \\
\text { tied, } \\
\mathrm{n}=934 \\
(\%)\end{array}$ & $\begin{array}{l}\mathrm{p} \text { - } \\
\text { value }\end{array}$ \\
\hline Breast-feeding only & $393(93.1)$ & $22(75.9)$ & $787(84.2)$ & $<0.001$ \\
\hline $\begin{array}{l}\text { Breast-feeding and } \\
\text { bottle-feeding }\end{array}$ & $15(3.6)$ & $1(3.4)$ & $40(4.3)$ & \\
\hline Bottle-feeding only & $14(3.3)$ & $6(20.7)$ & $107(11.5)$ & \\
\hline aFisher's exact test. & & & & \\
\hline
\end{tabular}

\section{Discussion}

Midwives performed neonatal frenotomies in the 19th century. In the 1960's, frenotomies decreased due to the rise of bottle feeding. With the increased popularity of breastfeeding, especially since the 1990's, there was a resurgence of interest in ankyloglossia $[1,4,6-8,10,13-15,20]$. Nowadays, approximately $80 \%$ of mothers in our area initiate breastfeeding. However, breastfeeding problems are common, keeping rates of breastfeeding lower than they should be $[3,8,9,18,31,32]$. Causes of early weaning include apparent breast refusal, inadequate milk intake, introduction of formula supplementation with a subsequent decrease in milk production, and breast and nipple pain $[6-9,13,15,18]$.

Lingual function is more important than appearance of the frenulum, and must be carefully evaluated as well. One of the most widely used tools to assess lingual function is HATLFF (Hazelbaker's Assessment Tool for Lingual Frenulum Function) score [28], which we used to evaluate our patients. Some tongue-ties restrict extension of the tongue beyond the lower gum and force the infant to use its jaw to keep the breast in the mouth and form a proper seal, making breastfeeding difficult $[1-6,12-14,16-18,20,25$, 32]. Research has shown that between 25 and $80 \%$ of tongue-tied infants have difficulty breastfeeding $[13,25,33]$. Even though most studies have not found any effects on bottle feeding, given the more passive efforts involved with it, a few authors have observed that tongue-tied infants may have trouble sucking from a bottle as well $[1,2,10-12,20]$. We believe that all the newborns should be explored to rule out the presence of a lingual frenulum and should be offered a frenotomy as soon as possible in case of ankyloglossia given the risk of breastfeeding cessation $[4,6-8,11-13,16,17,20,25]$. Frenotomy has shown to reduce maternal nipple pain in the short term, although improvement varies individually. Further randomized controlled trials of high methodological quality are warranted to determine longer term effects of frenotomy in terms of breastfeeding effectiveness, decrease in breast/nipple pain and feeding problems, increased duration of breastfeeding, and infants' growth $[9,16,17]$. Like Ballard and Hogan, we 
observed an improvement in $95.2 \%$ of cases. Sometimes improvement is not immediate because sore or traumatized nipples may take 24 to 72 hours to heal, and the infant may need time to re-learn suckling [2]. Ghaheri's prospective cohort study found an immediate improvement following frenotomy but also that breastfeeding continued to improve over the first month post-procedure [32]. Schlatter evaluated breastfeeding at the age of 2.5 weeks and found that only $13 \%$ of frenotomized neonates had breastfeeding problems following the procedure $[6,25]$. Messner found that $83 \%$ of infants with ankyloglossia were breastfed for at least two months, compared with $92 \%$ of control infants [10]. In our case, 415 of 451 (92.0\%) neonates with ankyloglossia were exclusively breastfed at discharge, and the percentage was higher in frenotomized infants, probably because mothers who accept a frenotomy are more prone to breastfeeding. We found that the rate of exclusive breastfeeding at discharge was higher among tongue-tied infants than non-tongue-tied infants (Table 1). When comparing treated and untreated infants, the rates of exclusive breastfeeding at discharge were significantly higher in favor of frenotomy (Table 2). These results could indicate that performing a frenotomy in tongue-tied infants may help establish breastfeeding. However, they must be cautiously interpreted because we did not have a formal control group.

The main limitation of our study is the lack of a formal control group. We offered the frenotomy to all tongue-tied patients and most parents consented to it. Due to the low risk of frenotomy and the risks of early weaning, we did not find it ethical to have a control group. Another limitation is that the group of mothers with tongue-tied neonates, despite being homogeneous with non-tongue-tied infants in regard to the variables we measured, may not be homogeneous in terms of motivation to breastfeed. This could justify the higher breastfeeding rate among the ankyloglossia group. Motivation for breastfeeding may be even more relevant among mothers who refused a frenotomy, for which comparisons with the 29 untreated infants must be interpreted cautiously. Parents who refused a frenotomy could be less motivated for breastfeeding, for which they preferred not to do any interventions. We measured short-term improvement in terms of maternal nipple pain by asking the mothers if they felt less pain after the procedure, but we did not use quantitative measures of pain. We used no quantitative measures of infant latch onto the breast but relied on lactation consultants' observation of the feeds according to the LATCH scale. Neither the observer nor the mother were blinded, because the objective of our study was to describe our current practice, not to demonstrate the effectiveness of the frenotomy. The mother was confident that thefrenotomy would solve her breastfeeding problems, and witnessing the procedure may have conditioned her immediate perception of the feed. All the parents were informed of the presence of ankyloglossia, which could have influenced them to believe that there would be problems breastfeeding. We took into account whether the mother had previously breastfed a baby; however, we did not analyze for how long or if exclusively. The intervention took place prior to the establishment of breastfeeding, and since sucking improves during the first days and weeks, the improvement could have been erroneously attributed to the intervention [1]. Our study has strengths as well. This is, as far as we know, the largest study published to date, which took place at one single center and was carried out by a small team of neonatologists. We need to analyze our group to look for the duration of breastfeeding. 


\section{Conclusions}

Frenotomy is a simple, safe, and effective procedure. In our study population, tongue-tied neonates who underwent a frenotomy were more likely breastfed at discharge from the maternity ward than those who did not undergo it.

\section{Abbreviations}

IBCLC: International Board Certified Lactation Consultant

\section{Declarations}

\section{Ethics approval and consent to participate}

The Ethics Committee of Hospital del Mar (CEImPSMAR) approved this project (reference number: 2019/8537/I). The Ethics Committee deemed it unnecessary to obtain a written consent form from the participants. This research was conducted ethically in accordance with the World Medical Association Declaration of Helsinki.

\section{Consent for publication}

Not applicable.

\section{Availability of data and material}

The datasets used and analyzed during this study are available from the corresponding author on reasonable request.

\section{Competing interests}

The authors have no financial relationships relevant to this article to disclose. I declare that I have no competing interests.

\section{Funding}

We declare that we have not received any funds or grants for this research.

\section{Authors' contributions}

SM designed the study, collected data, analyzed the results, drafted the initial manuscript, and approved the final manuscript as submitted.

LR instructed SM in distinguishing the different types of tongue-tie, helped analyze our results, helped draft the initial manuscript and approved the final manuscript as submitted. 
$\mathrm{JC}$ and $\mathrm{ML}$ helped collect data, helped draft the initial manuscript and approved the final manuscript as submitted.

XJ performed all the statistical analyses and helped the authors interpret them. He helped write the "Patients and methods" part and approved the final manuscript as submitted.

\section{Acknowledgements}

We would like to thank Jennifer Bricker-Bolton for proofreading this manuscript and helping with the English language.

\section{References}

1. Hall DM, Renfrew MJ. Tongue tie. Arch Dis Child 2005 Dec,90(12):1211-5. doi: 10.1136/adc.2005.077065

2. Ballard JL, Auer CE, Khoury JC. Ankyloglossia: assessment, incidence, and effect of frenuloplasty on the breastfeeding dyad. Pediatrics 2002,110(5), e63. doi: 10.1542/peds.110.5.e63

3. Edmunds J, Miles SC, Fulbrook P. Tongue-tie and breastfeeding: a review of the literature. Breastfeed Rev 2011,19(1):19-26

4. Segal LM, Stephenson R, Dawes M, Feldman P. Prevalence, diagnosis, and treatment of ankyloglossia: methodologic review. Can Fam Physician 2007 Jun,53(6):1027-33

5. Lalakea ML, Messner AH. Ankyloglossia: does it matter? Pediatr Clin North Am 2003,50(2):381-97. doi: 10.1016/s0031-3955(03)00029-4

6. Messner AH, Walsh J, Rosenfeld RM, Schwartz SR, Ishman SL, Baldassari C, Brietzke SE, Darrow DH, Goldstein N, Levi J, Meyer AK, Parikh S, Simons JP, Wohl DL, Lambie E, Satterfield L. Clinical Consensus Statement: Ankyloglossia in Children. Otolaryngol Head Neck Surg 2020 May,162(5):597611. doi: 10.1177/0194599820915457. Epub 2020 Apr 14

7. Becker S, Mendez MD. Ankyloglossia. 2020 Oct 1. In: StatPearls [Internet]. Treasure Island (FL): StatPearls Publishing, 2021 Jan

8. Hill R. Implications of Ankyloglossia on Breastfeeding. MCN Am J Matern Child Nurs 2019 Mar,44(2):73-9. doi:10.1097/NMC.0000000000000501

9. Frenectomy for the Correction of Ankyloglossia: A Review of Clinical Effectiveness and Guidelines [Internet]. Ottawa (ON): Canadian Agency for Drugs and Technologies in Health, 2016 Jun 15

10. Messner AH, Lalakea ML, Aby J, Macmahon J, Bair E. Ankyloglossia: incidence and associated feeding difficulties. Arch Otolaryngol Head Neck Surg 2000 Jan,126(1):36-9. doi: 10.1001/archotol.126.1.36

11. Hogan $M$, Westcott $C$, Griffiths $M$. Randomized, controlled trial of division of tongue-tie in infants with feeding problems. J Paediatr Child Health 2005,41:246-50. doi: 10.1111/j.1440-1754.2005.00604.x 
12. Ricke LA, Baker NJ, Madlon-Kay DJ, DeFor TA. Newborn tongue-tie: prevalence and effect on breastfeeding. J Am Board Fam Pract 2005,18(1),1-7. doi: 10.3122/jabfm.18.1.1

13. Manipon C. Ankyloglossia and the Breastfeeding Infant: Assessment and Intervention. Adv Neonatal Care 2016 Apr,16(2):108-13. doi:10.1097/ANC.0000000000000252

14. Walsh J, McKenna Benoit M. Ankyloglossia and Other Oral Ties. Otolaryngol Clin North Am 2019 Oct,52(5):795-811. doi:10.1016/j.otc.2019.06.008. Epub 2019 Jul 25

15. Matin T, Sun-Joo J, Simon D, Steven R, Bobak M. Ankyloglossia: Still a Matter of Controversy. AJBSR 2020,8(5):365-8. doi: 10.34297/AJBSR.2020.08.001303

16. O'Shea JE, Foster JP, O'Donnell CP, et al. Frenotomy for tongue-tie in newborn infants. Cochrane Database Syst Rev 2017 Mar 11,3(3):CD011065. doi:10.1002/14651858.CD011065.pub2

17. Shekher R, Lin L, Zhang R, Hoppe IC, Taylor JA, Bartlett SP, Swanson JW. How to Treat a Tongue-tie: An Evidence-based Algorithm of Care. Plast Reconstr Surg Glob Open 2021 Jan 25,9(1):e3336. doi: $10.1097 /$ GOX.0000000000003336

18. Campanha SMA, Martinelli RLC, Palhares DB. Association between ankyloglossia and breastfeeding. Codas 2019 Feb 25,31(1):e20170264. doi:10.1590/2317-1782/20182018264

19. Maya-Enero S, Pérez-Pérez M, Ruiz-Guzmán L, Duran-Jordà X, López-Vílchez MÁ. Prevalence of neonatal ankyloglossia in a tertiary care hospital in Spain: a transversal cross-sectional study. Eur J Pediatr 2021 Mar,180(3):751-7. doi: 10.1007/s00431-020-03781-7. Epub 2020 Aug 15

20. Knox I. Tongue Tie and Frenotomy in the Breastfeeding Newborn. NeoReviews 2010,11(9):e513-9. doi: 10.1542/neo.11-9-e513

21. Ghaheri BA, Tylor DA, Zaghi S. Lacking Consensus: The Management of Ankyloglossia in Children. Otolaryngol Head Neck Surg 2020 Nov,163(5):1064. doi:10.1177/0194599820937299

22. Messner AH, Simons JP, Walsh J. Ankyloglossia: Conscientious Use of Best Evidence Amid the Controversy. Otolaryngol Head Neck Surg 2020 Nov,163(5):1065. doi:10.1177/0194599820937298

23. Dollberg S, Botzer E, Grunis E, Mimouni FB. Immediate nipple pain relief after frenotomy in breast-fed infants with ankyloglossia: a randomized, prospective study. J Pediatr Surg 2006,41(9):1598-600. doi: 10.1016/j.jpedsurg.2006.05.024

24. Messner AH, Lalakea ML. Ankyloglossia: controversies in management. Int J Pediatr Otorhinolaryngol 2000,54(2-3):123-31. doi: 10.1016/s0165-5876(00)00359-1

25. Schlatter SM, Schupp W, Otten JE, Harnisch S, Kunze M, Stavropoulou D, Hentschel R. The role of tongue-tie in breastfeeding problems-A prospective observational study. Acta Paediatr 2019,108(12):2214-21. doi: 10.1111/apa.14924

26. National Institute for Health and Care Excellence, NICE: Division of anklyloglossia (tongue tie) for breastfeeding [Internet]. [cited 2021 Aug 5] Available from: https://www.nice.org.uk/sharedlearning/division-of-ankyloglossia-tongue-tie-for-breastfeeding

27. Coryllos EW, Genna CW, Salloum AC. Congenital tongue-tie and its impact on breastfeeding. American Academy of Pediatrics. Section on breastfeeding [Internet]. January 2004. Available from: 
https://www.researchgate.net/publication/301346077_Congenital_tonguetie_and_its_impact_on_breastfeeding

28. Hazelbaker AK. The Assessment Tool for Lingual Frenulum Function: Use in a Lactation Consultant Private Practice. Pasadena, CA: Pacific Oaks College, 1993.

29. Jensen D, Wallace S, Kelsay P. LATCH: a breastfeeding charting system and documentation tool. J Obstet Gynecol Neonatal Nurs 1994 Jan,23(1):27-32. doi: 10.1111/j.1552-6909.1994.tb01847.x

30. Pransky SM, Lago D, Hong P. Breastfeeding difficulties and oral cavity anomalies: The influence of posterior ankyloglossia and upper-lip ties. Int J Pediatr Otorhinolaryngol 2015,79(10):1714-7. doi: 10.1016/j.jporl.2015.07.033

31. Victora CG, Bahl R, Barros AJ, França GV, Horton S, Krasevec J, Murch S, Sankar MJ, Walker N, Rollins NC, Lancet Breastfeeding Series Group. Breastfeeding in the 21st century: epidemiology, mechanisms, and lifelong effect. Lancet 2016 Jan 30,387(10017):475-90. doi: 10.1016/S01406736(15)01024-7

32. Ghaheri BA, Cole M, Fausel SC, Chuop M, Mace JC. Breastfeeding improvement following tongue-tie and lip-tie release: A prospective cohort study. Laryngoscope 2017,127(5):1217-23. doi: 10.1002/lary. 26306

33. Francis DO, Krishnaswami S, McPheeters M. Treatment of ankyloglossia and breastfeeding outcomes: a systematic review. Pediatrics 2015,135(6):e1458-66. doi: 10.1542/peds.2015-0658 